\title{
Total Pancreatectomy With Islet Autotransplantation Improves Quality of Life in Patients With Refractory Recurrent Acute Pancreatitis
}

\author{
Melena D. Bellin, Tossapol Kerdsirichairat, Gregory J. Beilman, Ty B. Dunn, Srinath \\ Chinnakotla, Timothy L. Pruett, David R. Radosevich, Sarah J. Schwarzenberg, David E. R. \\ Sutherland, Mustafa A. Arain, and Martin L. Freeman \\ Departments of Medicine, Pediatrics, and Surgery, University of Minnesota, Minneapolis, \\ Minnesota
}

\begin{abstract}
BACKGROUND \& AIMS-Therapeutic options are limited for patients with recurrent acute pancreatitis who have intractable symptoms despite maximal endoscopic and medical treatment, but equivocal or no morphologic or functional evidence of chronic pancreatitis. We performed a prospective observational cohort study to determine the efficacy of total pancreatectomy with islet auto-transplantation (TPIAT) for these patients.
\end{abstract}

\begin{abstract}
METHODS-We collected data from all patients undergoing TPIAT at the University of Minnesota from 2007 through 2013; 49 patients (42 female; mean age, 32.8 - 7.8 years) had a diagnosis of recurrent acute pancreatitis not provoked by intervention, with negative or equivocal findings from non-diagnostic imaging or pancreatic function tests for chronic pancreatitis, and intractable pain between episodes. Data on insulin use, narcotic requirements, pain scores, and health-related quality of life were collected before TPIAT; 3 months, 6 months, and 1 year afterward; and then yearly.
\end{abstract}

RESULTS-All 49 patients studied required narcotics before TPIAT ( 45 daily users and 4 intermittent users); 2 had insulin-treated diabetes. At 1 year after TPIAT, 22 out of 48 patients (46\%) reported no use of narcotic pain medications ( $P<.001$ vs baseline). Health-related quality of life score, measured by the physical and mental component summary score, increased by approximately 1 standard deviation from the population mean $(P<.001$ for the physical component summary; $P=.019$ for the mental component summary). At 1 year after TPIAT, 21 out of 48 patients (45\%) were insulin independent; their mean percent glycosylated hemoglobin $\mathrm{A}_{1 \mathrm{c}}$ at 1 year after TPIAT was $6.0 \%-0.9 \%(5.2 \%-0.6 \%$ pre-TPIAT).

\footnotetext{
Address requests for reprints to: Martin L. Freeman, MD, University of Minnesota Medical Center, 406 Harvard Street SE, Minneapolis, Minnesota 55455. freem020@umn.edu; fax: 612 625-5620.

Conflicts of interest

The authors disclose no conflicts.

Supplementary Material

Note: To access the supplementary material accompanying this article, visit the online version of Clinical Gastroenterology and Hepatology at www.cghjournal.org, and at http://dx.doi.org/10.1016/j.cgh.2016.02.027.
} 
CONCLUSIONS-Patients with recurrent acute pancreatitis but lacking clear chronic pancreatitis benefit from TPIAT, with outcomes similar to those previously described for patients with chronic pancreatitis (improved quality of life and reduced narcotic use). For these patients who have otherwise limited surgical treatment options, TPIAT can be considered when medical and endoscopic therapies have failed.

\section{Keywords}

CP; HRQL; clinical trial; pancreas

Recurrent acute pancreatitis (RAP) may result from a wide variety of risk factors, including all of the causes of isolated episodes of pancreatitis. Despite advanced evaluation approximately $10 \%-20 \%$ of cases remain unexplained. Many proposed etiologies are controversial, particularly pancreas divisum and sphincter of Oddi dysfunction. ${ }^{1-5}$ The natural history of RAP often includes progression to chronic pancreatitis (CP), or in some cases intractable pain without clear evidence of CP. ${ }^{6,7}$ Efficacy of interventions including medical, endoscopic, or surgical is limited and controversial, in part because therapies may be addressing factors that are not in fact etiologic, such as proposed ductal obstruction, or because the patient has already developed subtle $\mathrm{CP},{ }^{1-3}$ or secondary to central sensitization of pain in which central nervous system pain perception is altered from the repeated stimuli of acute pancreatitis. ${ }^{8,9}$ Frequent hospitalizations, opioid analgesic dependency, disability, and reduced quality of life may result for such patients. Treatment options for patients refractory to such therapies are limited.

Total pancreatectomy with islet autotransplant (TPIAT) has been described as a treatment option for patients with overt CP unresponsive to medical and endoscopic therapy. ${ }^{10-12}$ For severely affected patients failing medical treatment, TPIAT can restore quality of life and relieve or lessen chronic pain burden in most patients. ${ }^{13-16}$ With this procedure the pancreas is completely resected, and the pancreatic islets are isolated and infused back into the recipient's portal vein, after which they engraft in the liver and produce insulin to prevent or minimize postsurgical diabetes. ${ }^{17,18}$ Overall, about $90 \%$ of those undergoing TPIAT have endogenous islet function, and one-third discontinue insulin therapy. ${ }^{10}$

TPIAT may also be offered to patients with intractable RAP. However, no study to date has examined specifically the efficacy of TPIAT for those patients with idiopathic RAP who have either severe recurrent episodes of pain or progression to daily chronic pain but lack a definitive diagnosis of CP. In the current study we report our experience with TPIAT for management of RAP, selecting for the cohort of patients who had clear documentation of RAP not provoked by endoscopic retrograde cholangiopancreatogram (ERCP) or other interventions, but who had equivocal or negative imaging and function tests for $\mathrm{CP}$.

\section{Methods}

\section{Subjects}

All patients undergoing TPIAT since 2007 at the University of Minnesota have been enrolled into an institutional review board approved prospective cohort study. Informed consent to 
participate in the study was obtained before TPIAT from all patients or parental consent with patient assent (for patients $<18$ years).

All patients undergoing TPIAT between January 1, 2007 and May 1, 2013 were identified who met our criteria for RAP $(\mathrm{N}=49)$. For this purpose, RAP was defined by (1) presence of 2 or more episodes of spontaneous acute pancreatitis (based on Atlanta criteria of pain and lipase or amylase elevation 3 times the upper limit of normal and/or compatible imaging findings), (2) lack of pancreatic calcifications, and (3) lack of clear imaging or functional evidence for CP (defined as having 2 or more of the following abnormalities: compatible parenchymal or ductal changes on magnetic resonance cholangiopancreatography, $\geq 4$ criteria on endoscopic ultrasound, and/or abnormal endoscopic pancreatic function tests). ${ }^{13,19-21}$ Patients with PRSS1 mutations were excluded, but those with other mutations, such as CFTR and SPINK 1, were included. Episodes of acute pancreatitis were considered only if spontaneous (ie, not induced by ERCP or other interventions).

\section{Surgical Procedure}

TPIAT was performed as previously described ${ }^{10,22}$ with total pancreatectomy, splenectomy, cholecystectomy, and partial duodenectomy, and with small bowel continuity restored by duodenoduodenostomy or Roux-en-Y duodenojejunostomy.

Islets were isolated as previously described. ${ }^{23}$ Briefly, each pancreas was infused intraductally with collagenase and neutral protease solution, followed by mechanical digestion using the semi-automated method of Ricordi et al, ${ }^{24}$ with density centrifugation only as indicated based on tissue volume. Islets were then infused intraportally into the recipient. Heparin was administered to prevent portal vein thrombosis, and intravenous insulin administered to maintain euglycemia to minimize metabolic stress on the newly implanted islet graft.

Biopsies were most often taken from head, neck, and body of the pancreas; the number of biopsies containing tissue ranged from 1-5 per patient (with tissue successfully obtained in 48 out of 49 cases). The original slides for each TPIAT were retrieved from the pathology archive, maintained by the department of pathology at University of Minnesota. Each specimen was read by a trained pathologist, as normal $(n=8)$, indicative of $\mathrm{CP}$ based on fibrosis with or without inflammation, and/or acinar atrophy $(n=37)$; or as peripancreatic fat necrosis without parenchymal changes of $\mathrm{CP}(\mathrm{n}=3){ }^{25}$

\section{Data Collection}

Patients were asked to prospectively complete health questionnaires that included insulin use history, pain and pain medication use, and health-related quality of life (HRQOL) assessed by the Rand Short Form-36 (SF-36). These were administered before surgery, and mailed to patients at 3 months, 6 months, 1 year, and then yearly after surgery. When completing health questionnaires, patients were asked to report average daily pain score over the preceding 4 weeks, using a Likert scale from 0 (no pain) to 10 (severe pain). 
Medical records were reviewed to confirm or provide additional data for insulin independence, insulin dose, metabolic laboratory parameters, pain scores, and pain medication usage.

Although attrition in patient response occurred over time, insulin use and narcotic use at 1 year are known for 48 out of 49 patients, all excepting 1 patient deceased before 1 year. Thus, 1 year is used as the primary outcome, with long-term follow-up out to 5 years provided as available.

\section{Laboratory Studies}

Patients had routine metabolic testing performed before surgery, and at 3 months, 6 months, and yearly after surgery. Evaluation included hemoglobin $\mathrm{A}_{1 \mathrm{c}}$ level $\left(\mathrm{HbA}_{1 \mathrm{c}}\right)$, fasting and stimulated glucose, and C-peptide levels, from a mixed meal tolerance test (Boost High Protein, $6 \mathrm{~mL} / \mathrm{kg}$, maximum $360 \mathrm{~mL}$, Nestle Health Science, NJ) with samples collected fasting and 1 and 2 hours after the mixed meal.

\section{Statistical Analyses}

Patient demographic descriptors are expressed as mean \pm standard deviation. Outcome mean measures are expressed as mean \pm standard error of the mean. Ordinal variables (hospitalization frequency, pain scores) are expressed as median (interquartile range [IQR], 25th-75th percentile). Statistical analyses were performed using SAS version 9.2 (SAS Institute Inc, Cary, NC). For analysis of the SF-36, mixed model methods were used to take into account within subject effects (ie, repeated measures for each patient) and to handle missing health surveys at some time points following TPIAT. Initial HRQOL analyses used physical component summary (PCS) and mental component summary (MCS) as mean outcome measures, to determine change over time, and effect of abnormal versus normal histopathology at the time of TPIAT. Subsequently, multivariable analysis was adjusted by age, gender, insulin use at 1 year, and narcotic use at 1 year, expressed as categorical variables. $P$ values expressed within the text reflect the multivariate model.

The proportion of patients on insulin or narcotics is expressed as a percentage of the total with follow-up at each time point posttransplant. Insulin and narcotic use at 1 year are compared with baseline by chi-square. C-peptide values fasting and stimulated at 1 year are compared with pre-TPIAT values with paired $t$ tests. To accommodate nonnormative values, median pain scores were compared with baseline using Wilcoxon nonparametric analyses. $P$ $<.05$ was considered statistically significant, with a Bonferroni adjustment applied for multiple time point comparisons (for pain scores, $0.05 / 6$ time points $=0.0083$; for narcotic use, $0.05 / 7$ time points $=0.007)$.

\section{Results}

\section{Patient Characteristics}

A total of 49 patients ( 42 female) met criteria for RAP as the primary indication for TPIAT, without CP. At the time of TPIAT, mean age was $32.8 \pm 7.8$ years (youngest 13 years), pain duration $7.9 \pm 7.8$ years, and interval since first documented episode of acute pancreatitis 5.3 
\pm 6.3 years. Proposed etiology of disease as diagnosed by the referring physician, and prior treatment history, are outlined in Table 1.

Patients were hospitalized for pancreatitis a median of 4 times (IQR, 3-5) in the year before TPIAT. None had been diagnosed with alcoholism or alcohol abuse; none were current alcohol users but $9(18 \%)$ were previous social drinkers (moderate in 3 cases, $\geq 2$ drinks/ day). Nineteen (39\%) were former or current smokers.

The mean duration post-TPIAT at time of analysis was $4.5 \pm 1.8$ years. Two patients are deceased: 1 at 4 months post-TPIAT and another at 3.4 years after TPIAT (causes of death were suicide and accidental drowning, respectively).

\section{Pain Symptoms Before and After Total Pancreatectomy With Islet Autotransplant}

Before surgery, the median daily pain score (IQR) was 5.5 (4-7); after TPIAT, applying a Bonferroni adjustment for multiple comparisons, median (IQR) pain scores were significantly reduced at 3 months $(2.5[1.5-6] ; P=.008), 1$ year $(2[1-4] ; P<.0001)$, and 2 years $(3[0-5] ; P=.001)$ after surgery (Figure 1$)$.

At the time of TPIAT, 45 patients (92\%) were using narcotic analgesics daily, whereas the remaining 4 received narcotics intermittently with hospitalizations. The proportion of patients requiring narcotics was reduced from baseline (Figure 2). At 1 year, 22 out of 48 (46\%) reported no use of narcotic pain medications ( $P<.001$ vs baseline). Narcotic use at 1 year was not associated with whether the patient had abnormal pathology $(P=.9)$.

\section{Health-Related Quality of Life, Before and After Total Pancreatectomy With Islet Autotransplant}

At 1 year after surgery, HRQOL improved; both the PCS and MCS scores from the SF-36 were significantly increased ( $P<.001$ for PCS; $P=.019$ for MCS), regardless of whether the patient had normal or abnormal histopathology (Figure 3). In multivariate linear regression adjusting for age, gender, pathology, insulin, and narcotic use, there was a possible trend toward better PCS in those patient no longer using narcotics at 1 year post-TPIAT $(P=.11)$. Statistically significant improvements were also observed in 7 of the 8 subscales of the SF-36 from baseline to 1 year for physical functioning, role-physical, bodily pain, general health, vitality, social functioning, and mental health $(P<.001)$.

Starting in 2011, health transition questions were added to the patient questionnaires to assess patient perception of pain and general health outcomes after the procedure. Among the 27 respondents at 1 year post-TPIAT, 26 (96\%) perceived their general health as much or somewhat better, and $26(96 \%)$ perceived their pain symptoms as much or somewhat better compared with before TPIAT.

\section{Insulin Requirements and Diabetes After Total Pancreatectomy With Islet Autotransplant}

Before surgery, there were 2 patients with insulin-treated diabetes mellitus. One year postTPIAT 21 out of 48 patients (44\%) were insulin independent, whereas another 14 out of 48 (29\%) used once-daily basal insulin (Figure $4 A$ ). Insulin dependence at 1 year was no different in the normal versus abnormal pathology groups $(P=.05)$. Mean $\mathrm{HbA}_{1 \mathrm{c}}( \pm$ 
standard error of the mean) before and up to 4 years post-TPIAT is displayed in Figure $4 B$. At 1 year $\mathrm{HbA}_{1 \mathrm{c}}$ was $6.0 \% \pm 0.16 \%$, with 33 out of 40 patients with available results (83\%) maintaining a $\mathrm{HbA}_{1 \mathrm{c}}<7 \%$. Mean fasting C-peptide at 1 year was $1.12 \pm 0.16 \mathrm{ng} / \mathrm{mL}$ versus $2.06 \pm 0.17 \mathrm{ng} / \mathrm{mL}$ at baseline $(P<.0001)$; mean stimulated C-peptide was $3.19 \pm 0.34$ $\mathrm{ng} / \mathrm{mL}$ versus $5.20 \pm 0.34 \mathrm{ng} / \mathrm{mL}$ at baseline $(P<.0001)$.

\section{Conclusions}

TPIAT has been described as a treatment for $\mathrm{CP}$, but has never been evaluated specifically as a treatment for refractory RAP. ${ }^{10,14,26-28}$ Because of limitations in efficacy of currently available therapies, and often disabling symptoms that persist between or after overt attacks of acute pancreatitis, we have included RAP as an indication for TPIAT. ${ }^{13}$ Patients at our center have undergone TPIAT if they had clearly documented episodes of spontaneous RAP, not provoked by ERCP or other interventions; had failed usual methods of therapy, such as endoscopic and medical pain management; or had progressed to frequent or daily intractable severe pain, but lacked definitive evidence of $\mathrm{CP}$ by imaging or functional studies. For these patients with RAP, pain symptoms, requirement for narcotic therapy, and quality of life improved significantly after TPIAT.

Although diabetes is an obvious concern for patients and providers when considering TP, most TPIAT recipients had well controlled blood glucoses by $\mathrm{HbA}_{1 \mathrm{c}}$ criteria 5 years postTPIAT. Approximately half were insulin-independent at 1 and 2 years out from surgery, with one-third remaining so at 5 years. These outcomes have not been directly compared with results in patients undergoing TPIAT for CP. However, we have previously reported at our institution an overall insulin independence rate of $28 \%$ at 1 year in post-TPIAT. ${ }^{10}$ Speculatively, patients with RAP may have incurred less pancreatic damage and fibrosis, and thereby benefitted from a higher islet mass isolated for transplant. ${ }^{29}$ Furthermore, because these patients have normal caliber pancreatic ducts, they are not candidates for surgical drainage procedures, such as lateral pancreaticojejunostomy (Puestow), which later compromise the islet isolation. ${ }^{10,30}$ Nevertheless, patients undergoing TPIAT for RAP should be carefully counseled on the trade-off of diabetes risk, and lifelong commitment to pancreatic enzyme therapy, for the potential of pain relief and restored quality of life.

RAP is a condition with few treatment options available. Individual episodes are managed with pain medications, intravenous fluid support and/or enteral nutrition, and treatment of complications. To prevent future attacks, any modifiable risk factors, such as cigarette smoking or alcohol consumption, are addressed. Endoscopic therapies may be used to treat anatomic issues, such as biliary and/or pancreatic ductal obstruction incorporating sphincterotomy for choledochocele or choledocholithiasis, pancreatic sphincter stenosis of the major papilla, minor papillotomy in the case of pancreas divisum, or dilation and stenting of pancreatic strictures. ${ }^{1-4}$ Aggressive intervention, especially by repetitive ERCP with stenting, can induce stricturing and parenchymal injury, especially in patients with pancreas divisum and suspected sphincter of Oddi dysfunction. ${ }^{1-4}$ Such putative etiologies may be coincidental rather than causative in the cohort of patients included in the current series. When interventional and pain management measures fail to reduce future attacks, few other treatment options remain. For the disabled or chronically narcotic dependent patient 
with RAP, TPIAT may offer potential reduction or resolution of pain symptoms and the possibility of narcotic independence. Because TPIAT is reserved for patients with intractable pain or significant impairment of quality of life, our cohort of patients with RAP had a high rate of chronic narcotic dependence, more so than might be expected conventionally in those with RAP. One likely explanation for chronic narcotic use in our patients is that most had CP by histopathology (often focal or mild CP), not yet evident on conventional imaging.

Histopathology was consistent with CP in 37 out of 49 patients (76\%) in our RAP cohort. This finding suggests lack of sensitivity of our current tests to detect early stage $\mathrm{CP}$, or alternatively, it may reflect that our criteria were designed to require a high degree of certainty in the diagnosis of $\mathrm{CP}$ for the purpose of TPIAT candidacy evaluation, such as 4 or 5 of 9 criteria by endoscopic ultrasound, or any single other study suggesting $\mathrm{CP}$ in the absence of pancreatic calcifications, is considered insufficient to make a definitive diagnosis of $\mathrm{CP}$ at our institution. ${ }^{13}$

Although some patients do have complete relief of pain, others report reduced pain burden but remain on narcotic therapy. TPIAT was successful in allowing narcotic discontinuation in about half of our patients, but about half remained on narcotic therapy. Notably, a trend of increasing median pain scores at 3-4 years suggests possible recurrent or persistent pain caused by complications or comorbidities that need to be addressed in this complex population. Incomplete response may be related to comorbidities, such as gastrointestinal motility disorders including gastroparesis (occurring in 16\%). In addition, central sensitization from chronic or repeated episodes of pain, and opioid-induced hyperalgesia may all contribute to ongoing pain symptoms. ${ }^{9,31-35}$ For these reasons, all patients at our institution are currently followed by pain management and health psychology, with goal to transition back to a local pain management physician.

Narcotic use as a binary outcome measure lacks sensitivity. Many patients on narcotics used lesser doses after than before surgery, although we lacked sufficient prospective data to calculate morphine equivalents for this analysis. Even more critical is the functional status of the patient. The HRQOL analysis supports improved physical and mental functioning in this cohort following treatment. Although most patients in this cohort did have histologic evidence of noncalcific $\mathrm{CP}$ (which was equivocal or not visualized on preoperative imaging), whether pathology was abnormal did not impact narcotic use or HRQOL scores at 1 year.

Although most patients in this population with highly disabling RAP had favorable response to TPIAT, 2 patients were deceased at time of study, including 1 patient who committed suicide. Although this latter patient had a history of RAP, pancreatic pathology at surgery was normal, raising concern for other cause of chronic pain. This case clearly highlights the need for thorough medical and psychosocial evaluation and to provide adequate psychological support during the often long and challenging recovery from the major surgery of TPIAT.

Future studies within this subset of patients are warranted to answer remaining questions and improve outcomes, including ability to allow patients to discontinue narcotic therapy. The optimal time for intervening is not known, nor even the optimal criteria for selecting patients 
for TPIAT, to avoid major surgery and risk of diabetes for those patients who may fair less well and be best maintained on medical management for pain and acute pancreatitis attacks. Furthermore, we are unable to assess in this small cohort whether putative etiology of disease impacted long-term outcomes, an important consideration given that some of the proposed diagnoses, such as pancreas divisum and sphincter of Oddi dysfunction, are highly controversial and perhaps coincidental rather than causative. Interestingly, a female predominance was seen in this cohort, possibly reflecting a referral bias; we have seen a similar distribution of females to males in $\mathrm{CP},{ }^{10}$ but with more severe fibrosis in female compared with male patients (unpublished data), suggesting that male patients are referred at a later stage of disease.

In conclusion, TPIAT for RAP resulted in reduced pain burden and improved quality of life. Approximately one-half of patients were able to discontinue insulin therapy, with most regardless of insulin use, maintaining sufficient glycemic control to minimize risk of later diabetes complications. Further results from the increasing number of centers performing TPIAT will be of great interest.

\title{
Supplementary Material
}

Refer to Web version on PubMed Central for supplementary material.

\section{Acknowledgments}

Funding

Melena D. Bellin is supported by 5K23DK084315.

\author{
Abbreviations used in this paper \\ CP chronic pancreatitis \\ ERCP endoscopic retrograde cholangiopancreatogram \\ HRQOL health-related quality of life \\ IQR interquartile range \\ MCS mental component summary \\ PCS physical component summary \\ RAP recurrent acute pancreatitis \\ SF-36 Short Form-36 \\ TPIAT total pancreatectomy with islet autotransplant
}

\section{References}

1. Guda NM, Romagnuolo J, Freeman ML. Recurrent and relapsing pancreatitis. Curr Gastroenterol Rep. 2011; 13:140-149. [PubMed: 21286872] 
2. Romagnuolo J, Guda N, Freeman M, et al. Preferred designs, outcomes, and analysis strategies for treatment trials in idiopathic recurrent acute pancreatitis. Gastrointest Endosc. 2008; 68:966-974. [PubMed: 18725158]

3. Testoni PA. Acute recurrent pancreatitis: etiopathogenesis, diagnosis and treatment. World $\mathbf{J}$ Gastroenterol. 2014; 20:16891-16901. [PubMed: 25493002]

4. Roberts JR, Romagnuolo J. Endoscopic therapy for acute recurrent pancreatitis. Gastrointest Endosc Clin North Am. 2013; 23:803-819.

5. Bertin C, Pelletier AL, Vullierme MP, et al. Pancreas divisum is not a cause of pancreatitis by itself but acts as a partner of genetic mutations. Am J Gastroenterol. 2012; 107:311-317. [PubMed: 22158025]

6. Yadav D, O'Connell M, Papachristou GI. Natural history following the first attack of acute pancreatitis. Am J Gastroenterol. 2012; 107:1096-1103. [PubMed: 22613906]

7. Wilcox CM, Yadav D, Ye T, et al. Chronic pancreatitis pain pattern and severity are independent of abdominal imaging findings. Clin Gastroenterol Hepatol. 2015; 13:552-560. quiz e28-29. [PubMed: 25424572]

8. Bouwense SA, de Vries M, Schreuder LT, et al. Systematic mechanism-orientated approach to chronic pancreatitis pain. World J Gastroenterol. 2015; 21:47-59. [PubMed: 25574079]

9. Woolf CJ. Central sensitization: implications for the diagnosis and treatment of pain. Pain. 2011; 152:S2-S15. [PubMed: 20961685]

10. Sutherland DE, Radosevich DM, Bellin MD, et al. Total pancreatectomy and islet autotransplantation for chronic pancreatitis. J Am Coll Surg. 2012; 214:409-424. [PubMed: 22397977]

11. Dixon J, DeLegge M, Morgan KA, et al. Impact of total pancreatectomy with islet cell transplant on chronic pancreatitis management at a disease-based center. The American Surgeon. 2008; 74:735-738. [PubMed: 18705576]

12. Garcea G, Pollard CA, Illouz S, et al. Patient satisfaction and cost-effectiveness following total pancreatectomy with islet cell transplantation for chronic pancreatitis. Pancreas. 2013; 42:322328. [PubMed: 23407482]

13. Bellin MD, Freeman ML, Schwarzenberg SJ, et al. Quality of life improves for pediatric patients after total pancreatectomy and islet autotransplant for chronic pancreatitis. Clin Gastroenterol Hepatol. 2011; 9:793-799. [PubMed: 21683160]

14. Wilson GC, Sutton JM, Abbott DE, et al. Long-term outcomes after total pancreatectomy and islet cell autotransplantation: is it a durable operation? Ann Surg. 2014; 260:659-665. discussion 6567. [PubMed: 25203883]

15. Sutton JM, Schmulewitz N, Sussman JJ, et al. Total pancreatectomy and islet cell autotransplantation as a means of treating patients with genetically linked pancreatitis. Surgery. 2010; 148:676-685. discussion 85-86. [PubMed: 20846557]

16. Ahmad SA, Lowy AM, Wray CJ, et al. Factors associated with insulin and narcotic independence after islet autotransplantation in patients with severe chronic pancreatitis. J Am Coll Surg. 2005; 201:680-687. [PubMed: 16256909]

17. Bellin MD, Freeman ML, Gelrud A, et al. Total pancreatectomy and islet autotransplantation in chronic pancreatitis: recommendations from PancreasFest. Pancreatology. 2014; 14:27-35. [PubMed: 24555976]

18. Bellin MD, Balamurugan AN, Pruett TL, et al. No islets left behind: islet autotransplantation for surgery-induced diabetes. Curr Diab Rep. 2012; 12:580-586. [PubMed: 22777430]

19. Banks PA, Freeman ML. Practice Parameters Committee of the American College of Gastroenterology. Practice guidelines in acute pancreatitis. Am J Gastroenterol. 2006; 101:2379_ 2400. [PubMed: 17032204]

20. Catalano MF, Sahai A, Levy M, et al. EUS-based criteria for the diagnosis of chronic pancreatitis: the Rosemont classification. Gastrointest Endosc. 2009; 69:1251-1261. [PubMed: 19243769]

21. Conwell DL, Lee LS, Yadav D, et al. American Pancreatic Association Practice Guidelines in Chronic Pancreatitis: evidence-based report on diagnostic guidelines. Pancreas. 2014; 43:11431162. [PubMed: 25333398] 
22. Chinnakotla S, Bellin MD, Schwarzenberg SJ, et al. Total pancreatectomy and islet autotransplantation in children for chronic pancreatitis: indication, surgical techniques, postoperative management, and long-term outcomes. Ann Surg. 2014; 260:56-64. [PubMed: 24509206]

23. Balamurugan, GL., Lockridge, A., Soltani, SM., et al. Islet isolation from pancreatitis pancreas for autologous islet isolation. In: Islam, M., editor. Islet of Langerhans. 2. Dordrecht: Springer; 2014. p. 1199-1228.

24. Ricordi C, Lacy PE, Finke EH, et al. Automated method for isolation of human pancreatic islets. Diabetes. 1988; 37:413-420. [PubMed: 3288530]

25. Ammann RW, Heitz PU, Kloppel G. Course of alcoholic chronic pancreatitis: a prospective clinicomorphological long-term study. Gastroenterology. 1996; 111:224-231. [PubMed: 8698203]

26. Clayton HA, Davies JE, Pollard CA, et al. Pancreatectomy with islet autotransplantation for the treatment of severe chronic pancreatitis: the first 40 patients at the leicester general hospital. Transplantation. 2003; 76:92-98. [PubMed: 12865792]

27. Wilson GC, Ahmad SA, Schauer DP, et al. Cost-effectiveness of total pancreatectomy and islet cell autotransplantation for the treatment of minimal change chronic pancreatitis. J Gastrointest Surg. 2015; 19:46-54. discussion, 5. [PubMed: 25095749]

28. Morgan K, Owczarski SM, Borckardt J, et al. Pain control and quality of life after pancreatectomy with islet autotransplantation for chronic pancreatitis. J Gastrointest Surg. 2012; 16:129-133. discussion 33-34. [PubMed: 22042566]

29. Kobayashi T, Manivel JC, Carlson AM, et al. Correlation of histopathology, islet yield, and islet graft function after islet auto-transplantation in chronic pancreatitis. Pancreas. 2011; 40:193-199. [PubMed: 21404456]

30. Morgan KA, Theruvath T, Owczarski S, et al. Total pancreatectomy with islet autotransplantation for chronic pancreatitis: do patients with prior pancreatic surgery have different outcomes? Am Surg. 2012; 78:893-896. [PubMed: 22856498]

31. Bouwense SA, Ahmed Ali U, ten Broek RP, et al. Altered central pain processing after pancreatic surgery for chronic pancreatitis. Br J Surg. 2013; 100:1797-1804. [PubMed: 24227367]

32. Pasricha PJ. Unraveling the mystery of pain in chronic pancreatitis. Nat Rev Gastroenterol Hepatol. 2012; 9:140-151. [PubMed: 22269952]

33. Wilder-Smith $\mathrm{OH}$. Chronic pain and surgery: a review of new insights from sensory testing. J Pain Palliat Care Pharmacother. 2011; 25:146-159. [PubMed: 21657862]

34. Chu LF, Angst MS, Clark D. Opioid-induced hyperalgesia in humans: molecular mechanisms and clinical considerations. Clin J Pain. 2008; 24:479-496. [PubMed: 18574358]

35. Chowdhury RS, Forsmark CE, Davis RH, et al. Prevalence of gastroparesis in patients with small duct chronic pancreatitis. Pancreas. 2003; 26:235-238. [PubMed: 12657948] 


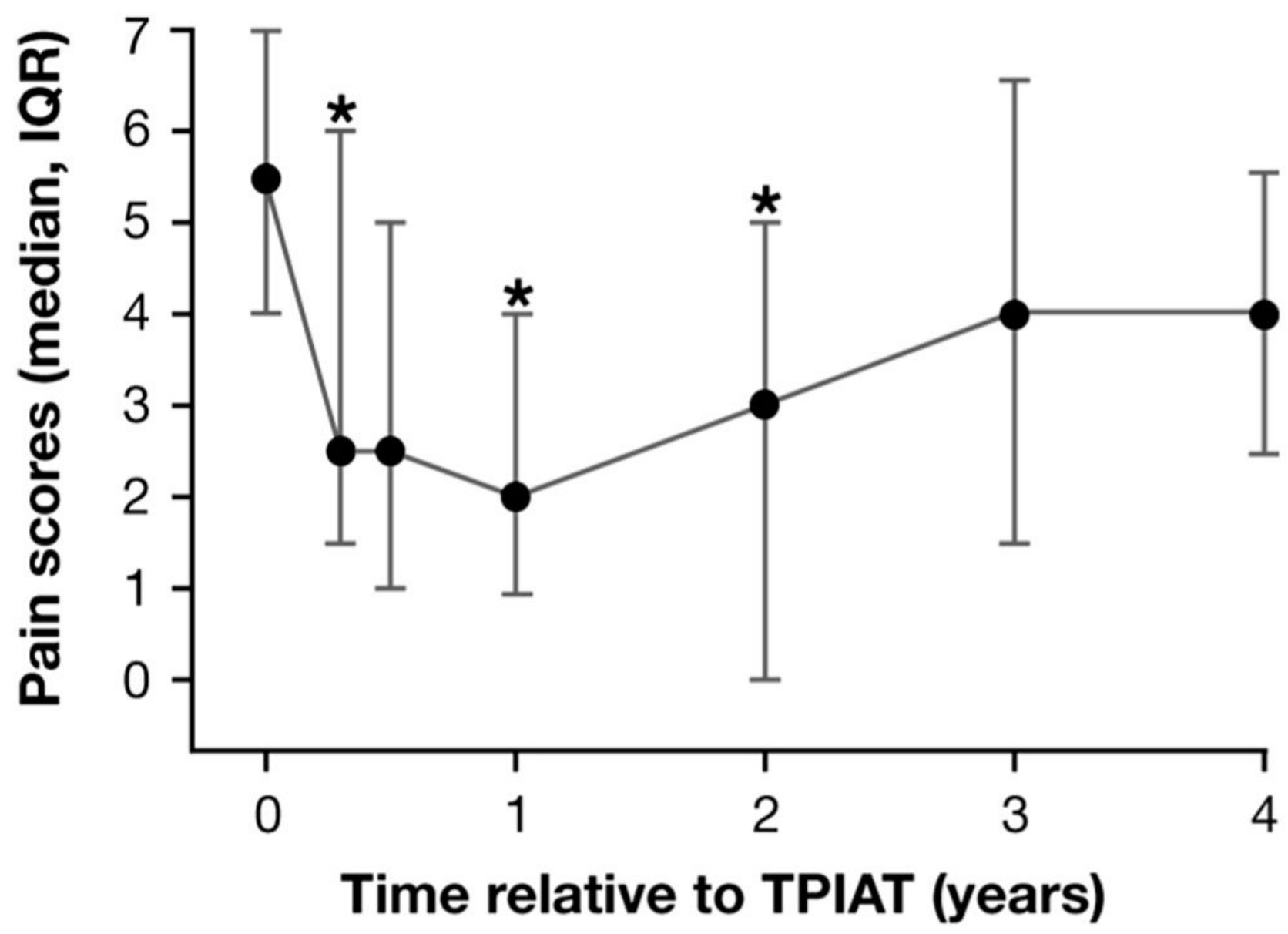

${ }^{*} P<.008$, significant after Bonferroni adjustment

Figure 1.

Median pain scores (with IQR) by duration post-TPIAT.

$* P<.008$ significant after Bonferroni adjustment 


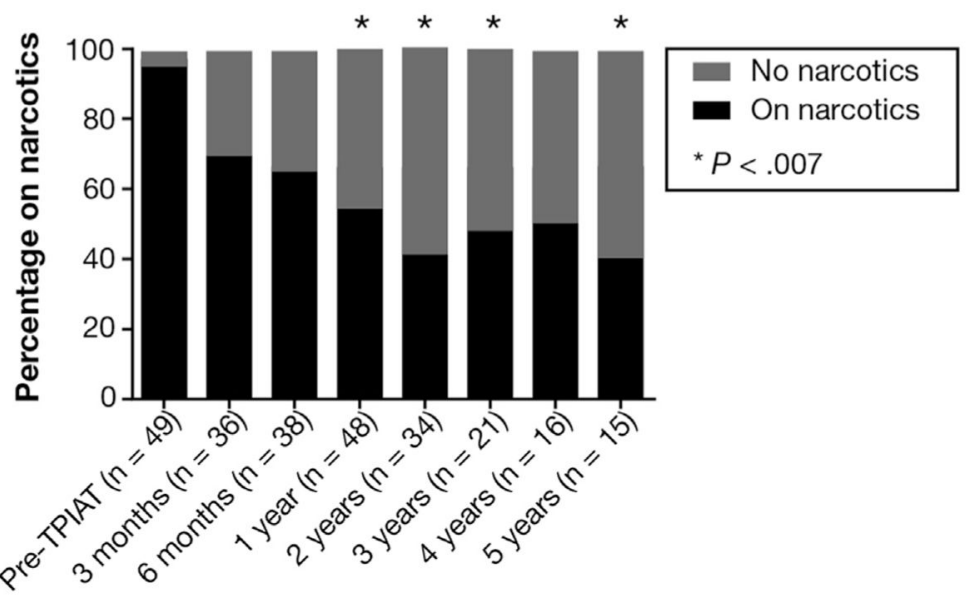

Time relative to TPIAT

Figure 2.

Proportion of patients requiring narcotic medications for pain management at each time point after TPIAT. 


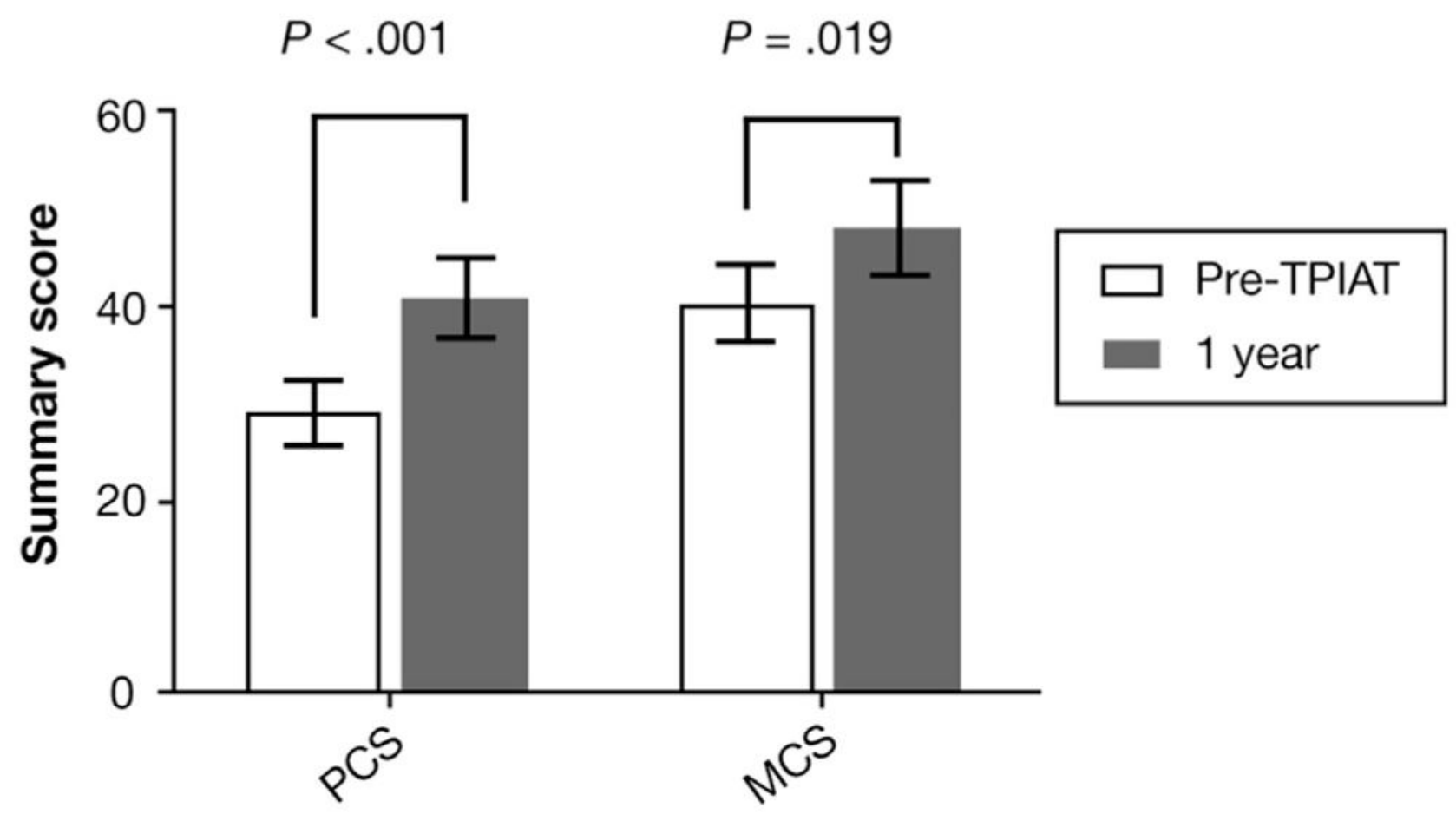

Figure 3.

Health-related quality of life before and 1 year after TPIAT as derived from patient completion of SF-36, with mean values and error bars indicating lower and upper confidence interval. 

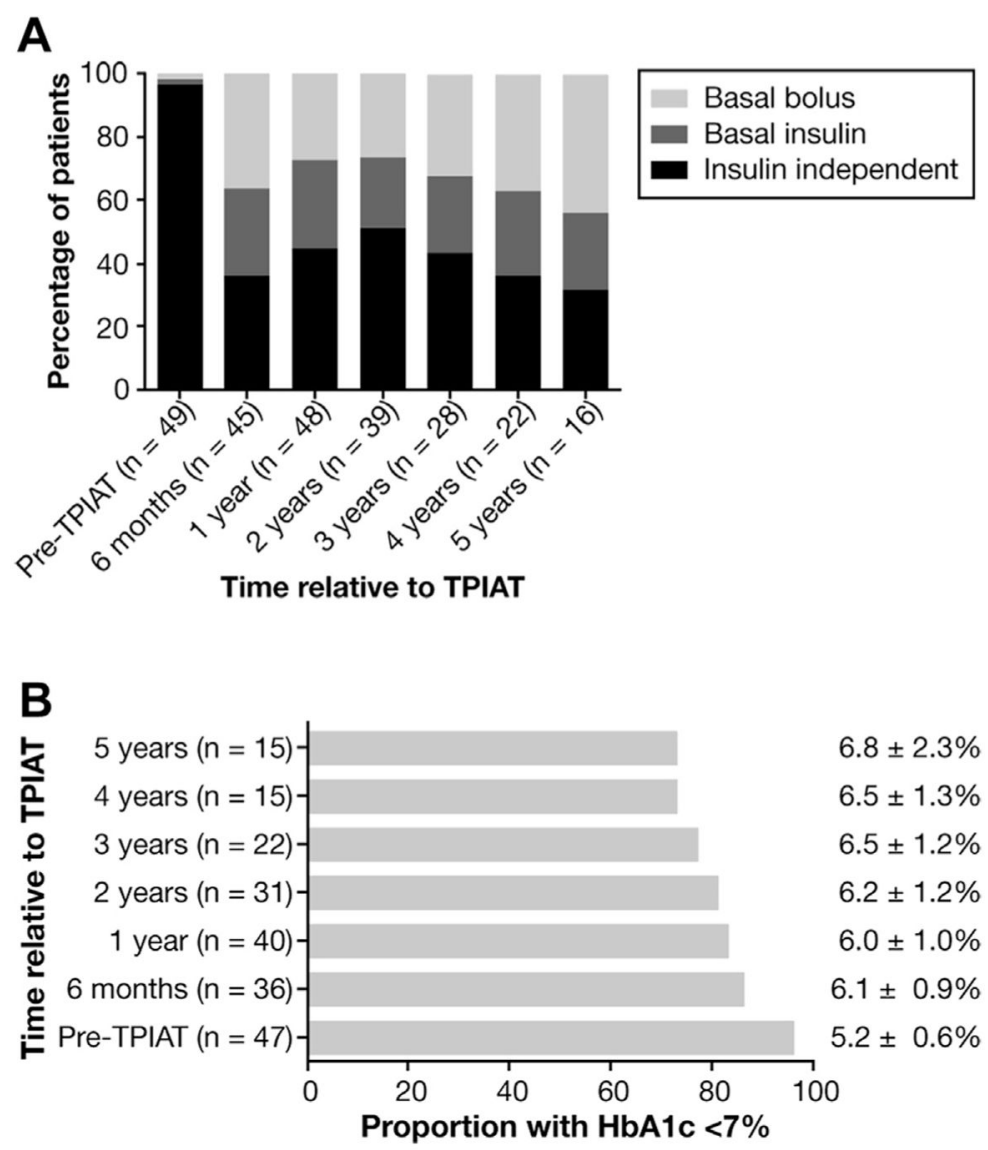

Figure 4.

Metabolic outcomes of TPIAT recipients. ( $A$ ) Insulin requirements before and after TPIAT, categorized as independent, basal insulin, or basal bolus (multiple daily injections). $(B)$ $\mathrm{HbA}_{1 \mathrm{c}}$, displayed as proportion with $\mathrm{HbA}_{1 \mathrm{c}}<7 \%$ and mean $\mathrm{HbA}_{1 \mathrm{c}} \pm$ standard error of the mean. 


\section{Table 1}

Characteristics of the 49 Subjects With RAP

\begin{tabular}{|c|c|}
\hline & Mean $\pm \mathrm{SD}$ (or median $[\mathrm{IQR}]$ as indicated) \\
\hline Age, $y$ & $32.8 \pm 7.8$ \\
\hline $\mathrm{n}<18$ years old $(\%)$ & $6(12)$ \\
\hline Gender, $\mathrm{n}(\%)$ female & $42(86)$ \\
\hline BMI, $k g / m^{2}$ & $24.5 \pm 5.3$ \\
\hline Time since diagnosis, $y$ & $5.3 \pm 6.3$ \\
\hline Number hospitalizations, 1 year prior & Median 4 (3-5) \\
\hline Daily pain symptoms reported, $\mathrm{n}(\%)$ & $45(91)$ \\
\hline \multicolumn{2}{|l|}{ Associated prereferral proposed diagnoses, $\mathrm{n}(\%)$} \\
\hline Idiopathic & $18(37)$ \\
\hline Sphincter of Oddi dysfunction & $14(29)$ \\
\hline Pancreas divisum & $11(22)$ \\
\hline Genetic & $4(8)$ \\
\hline Other & $2(4)$ \\
\hline \multicolumn{2}{|l|}{ ERCP with papillotomy/stent, n (\%) } \\
\hline Single ERCP procedure & $6(12)$ \\
\hline Multiple ERCP procedures & $40(82)$ \\
\hline \multicolumn{2}{|l|}{ Current/prior treatment with, $\mathrm{n}(\%)$} \\
\hline Jejunal feeds & $12(25)$ \\
\hline Total parenteral nutrition & $11(22)$ \\
\hline Pancreatic enzyme therapy & $34(70)$ \\
\hline Prior cholecystectomy, n (\%) & $42(86)$ \\
\hline Celiac plexus block & $7(14)$ \\
\hline \multicolumn{2}{|l|}{ Smoking status, $\mathrm{n}(\%)$} \\
\hline Current & $15(31)$ \\
\hline Former & $4(8)$ \\
\hline Diagnosis of gastroparesis & $8(16)$ \\
\hline \multicolumn{2}{|l|}{ Histopathology, from TPIAT, n (\%) } \\
\hline Normal pancreas & $8(17)$ \\
\hline Peripancreatic fat necrosis & $3(6)$ \\
\hline Chronic pancreatitis & $37(77)$ \\
\hline Pre-existing diabetes mellitus, n (\%) & $2(4)$ \\
\hline Islet mass transplanted (islet equivalents) & $307,468 \pm 143,335$ \\
\hline Islet mass dose (islet equivalents/kg body weight) & $4671 \pm 2109$ \\
\hline
\end{tabular}

BMI, body mass index; SD, standard deviation. 